\title{
QUANDO ARTEFATOS CULTURAIS FAZEM-SE CURRÍCULO E PRODUZEM SUJEITOS
}

\author{
WHEN CULTURAL ARTIFACTS MAKE UP CURRICULUM AND PRODUCE SUBJECTS
}

CUANDO LOS ARTEFACTOS CULTURALES SE HACEN CURRÍCULO Y PRODUCEN SUJETOS

MAKNAMARA, Marlécio 1

\section{RESUMO}

Este artigo aborda a música como artefato cultural que interessa ao campo educacional diante das disputas pelo privilégio sobre a educação das pessoas e de suas "vontades de sujeito". Retoma e amplia resultados de pesquisa sobre o currículo de um estilo musical para ilustrar como um artefato cultural aparentemente inócuo pode ser investigado e significado como máquina de ensinar. Sugere contribuições metodológicas a quem se lança à tarefa de investigar artefatos culturais segundo o referencial teórico pós-crítico. Conclui que é urgente explicitar as artimanhas que tornam currículos de artefatos culturais tão eficazes em suas capacidades de recrutar, produzir e regular sujeitos.

Palavras-chave: Currículo. Artefatos culturais. Produção de sujeitos.

\section{ABSTRACT}

This article discusses music as a cultural artifact of interest to the educational field in the face of disputes over the privilege of educating people and its "subject wills". Revisits and broadens research results on the curriculum of a musical style to illustrate how a seemingly innocuous cultural artifact can be investigated and signified as a teaching machine. It suggests methodological contributions to those who undertake the task of investigating cultural artifacts according to the post-critical theories. It concludes that it is urgent to spell out the gimmicks that make cultural artifact curricula so effective in their ability to recruit, produce, and regulate subjects.

Keywords: Curriculum. Cultural artifacts. Subject production.

\section{RESUMEN}

Este artículo mira la música como un artefacto cultural de interés para el campo educativo frente a disputas sobre el privilegio de la educación de personas y a sus "voluntades de sujetos". Revisa y amplía resultados de investigación sobre el currículo de un estilo musical para ilustrar cómo un artefacto cultural aparentemente inocuo puede investigarse y significarse como máquina de enseñanza. Sugiere contribuciones metodológicas a quienes tienen la tarea de investigar artefactos culturales bajo marco teórico poscrítico. Concluye que es urgente explicar los trucos que hacen que los currículos de artefactos culturales sean tan efectivos en su capacidad de reclutar, producir y regular sujetos.

Palabras clave: Currículo. Artefactos culturales. Producción de sujetos.

\footnotetext{
${ }^{1}$ Universidade Federal de Alagoas - UFAL - Maceió - Alagoas - Brasil.
} 


\section{INTRODUÇÃO}

No mundo contemporâneo novas configurações culturais têm concorrido com a escola pelo privilégio sobre a educação das pessoas. Tem-se ressaltado que muitas das representações ${ }^{2}$ disponibilizadas em diferentes artefatos culturais não apenas "chegam" às escolas, mas também entram em conflito com o que nelas se ensina. Há um "novo estado da cultura" que se caracteriza por "uma ampliação dos lugares em que nos informamos, em que de alguma forma aprendemos a viver, a sentir e a pensar sobre nós mesmos" (FISCHER, 1997, p. 62). Há uma "cultura da mídia" que tem fornecido "os modelos daquilo que significa ser homem ou mulher, bem-sucedido ou fracassado, poderoso ou impotente" (KELLNER, 2001, p. 9). Artefatos ${ }^{3}$ como a televisão, o cinema, os jornais, a literatura, o rádio, as revistas, os brinquedos, a música, etc. passam a ser vistos, nas palavras de Giroux (2001), como "máquinas de ensinar". No deslocamento engendrado por tais máquinas, são aprendidas novas habilidades, capacidades, modelos de sociabilidade e afetividade.

Os artefatos produzidos e divulgados na cultura da mídia mostram-se cada vez mais importantes, já que são "um produto social, o local no qual o significado é negociado e fixado, em que a diferença e a identidade são produzidas e fixadas, em que a desigualdade é gestada" (COSTA, 2005, p. 138). Os diferentes artefatos acionados pela cultura da mídia constituem textos curriculares, textos que precisam ser analisados em suas capacidades de governar e de produzir sujeitos. Isso é possível graças a dois aspectos. De um lado porque artefatos culturais, como todo currículo, encontram-se implicados em processos de regulação de condutas através de saberes que "circunscrevem aquilo que pode ser pensado sobre essas condutas" (SILVA, 2003, p. 191). Por outro lado, porque, de acordo com Silva (2001a), o texto de todo currículo é um texto eivado de poder - prescreve saberes, modos de ser, de pensar e de agir, indicando pensamentos, valores, exercícios e atitudes a serem praticados no sentido de constituição de tipos particulares de sujeito.

Neste artigo abordo conexões entre educação e cultura da mídia a partir dos estudos curriculares de orientação pós-crítica. Parto do pressuposto de que um currículo tem "vontade de sujeito" (CORAZZA, 2004) e produz subjetividades (SILVA, 2001b). Por meio da noção de "currículo cultural" extra-escolar, retomo e amplio resultados obtidos anteriormente sobre o currículo de um estilo musical para argumentar que, quando informações, aprendizagens, sentimentos e pensamentos são articulados, está-se compondo o texto de um currículo. Após esta introdução, situo a música como artefato da cultura da mídia que interessa ao campo educacional. Em seguida, sintetizo procedimentos metodológicos e resultados de pesquisa para ilustrar como um artefato cultural aparentemente inócuo pode ser investigado e significado como máquina de ensinar, como artefato que governa e produz sujeitos. Adiante, considerando a insidiosidade de artefatos culturais na constituição de modos de ser sujeito, proponho possíveis contribuições metodológicas a quem se lança à tarefa de investigá-los segundo o referencial aqui adotado. Por fim, teço algumas considerações referentes ao compromisso de investigar currículos de artefatos culturais.

\footnotetext{
${ }^{2}$ Aqui entendida como "a face material, visível, palpável, do conhecimento" (SILVA, 2001a, p. 32).

${ }^{3}$ Artefatos culturais resultam de um processo de construção e vinculação de significados culturais a diferentes objetos constituídos material e simbolicamente em uma cultura (CAMOZZATO, 2018).
} 


\section{MÚSICA NA CULTURA4 DA MÍDIA: UMA QUESTÃO DE EDUCAÇÃO E DE GOVERNO}

Se há tantos currículos culturais não-escolares sendo engendrados na cultura da mídia, por que enfatizar aqueles provenientes da música? Essa pergunta surgiu em Maknamara (2014) e aqui retomo sinteticamente as respostas: porque há música na escola, porque é musical a vida de quem vai à escola, porque a música também ensina e faz escola dentro e fora das instituições escolares.

Desde o início de minha juventude acompanhei alguns dos variados efeitos da música sobre nossos modos de ser, estar e se comportar no mundo. Contudo, foi como professor formador de professores/as que tais efeitos foram ficando cada vez mais evidentes para mim. Nas minhas atividades docentes, não só adquiri o hábito de tomar a música como recurso didático, como também passei a problematizá-la nas funções que opera no currículo escolar. Como professor de diferentes disciplinas ligadas à formação de docentes, também pude acompanhar nas escolas públicas aquilo que se costuma chamar de "erotização" 5 de meninos e meninas, expressa nas músicas que irrompiam em seus celulares durante as aulas; em danças realizadas durante o recreio em meio a um repertório musical escolhido por eles/as mesmos/as; em pichações de carteiras feitas por alunos e alunas que se atribuem adjetivos e atributos veiculados e valorizados pelas músicas que sinalizavam ouvir. Curioso quanto ao que observava nas escolas, interrogava os/as docentes sobre o que pensavam acerca de todo esse fenômeno. Não raro, obtinha respostas como "é assim mesmo!", "é da cultura deles!", ou "com essas músicas, o que você espera que se aprenda?!".

A música ocupa uma posição central no cenário cultural contemporâneo, no qual há uma "cultura da mídia" que "passou a dominar a vida cotidiana" (KELLNER, 2001, p. 11). Ao apontar para tal produtividade da música, Sovik (2000) vê a chamada "música popular" no Brasil como algo que compõe uma "sabedoria ready-made" e que constitui o "discurso identitário brasileiro que mais freqüentemente se atualiza" (p. 247). Corroborando essas observações, Napolitano (2005, p. 111) ressalta que no Brasil a música "possui uma importância cultural e política que tem muito pouco paralelo em outros países". Especificamente à juventude brasileira, embora seja possível que os/as jovens não prestem atenção àquilo que estão cantando ou não reflitam sobre aquilo que ouvem, eles e elas estabelecem relações entre as narrativas das canções e suas vidas (GARBIN et al, 2003).

Ao compor a cultura da mídia e se fazer cada vez mais presente nas escolas (MAKNAMARA e PARAÍSO, 2012; MAKNAMARA, 2014), a música se torna um objeto privilegiado também para o campo educacional, para além de sua obrigatoriedade e das funções que pode desempenhar como componente curricular. Considerando-se que há toda uma maquinaria não-escolar atribuindo significados a lugares, coisas, fenômenos, práticas e sujeitos, tem-se reconhecido que diferentes

\footnotetext{
${ }^{4}$ Cultura diz respeito "aos significados, aos conceitos, às ideias, às práticas, aos sentimentos, às relações e às emoções que um grupo cria, mobiliza, adota e recria em suas relações nos mais diferentes espaços" (PARAíso, 2010, p. 35). Kellner (2003, p. 107) usa Cultura da mídia para se referir ao "assalto das imagens, mensagens e espetáculos da mídia que inundam nossa cultura".

${ }^{5}$ Entendo tal erotização como uma produção cultural em torno do que deveria ou não ser preservado em termos de gênero e de sexualidade.
} 
artefatos culturais constituem um currículo, um currículo cultural que tem sido problematizado por diferentes pesquisas em educação de modo geral e pelas pesquisas curriculares de modo particular. A noção de currículo cultural destaca a importância de serem investigados "outros currículos (além do escolar) que contribuem para a formação das pessoas e que disputam espaço na produção de sentidos e dos sujeitos" (PARAísO, 2007, p. 24).

Na cultura da mídia, a dimensão de "luta pela imposição de significados" (SILVA, 2001a) é expressa por meio de discursos, imagens e eventos, os quais "vinculam-se à retórica, a lutas, a programas, e a ações políticas" (KELLNER, 2001, p. 123). Assim, naquilo que a cultura da mídia tem de produtivo em termos de significados e posições de sujeito, é possível ver uma "textualidade". Como um currículo não-escolar que se faz presente na escola, a música envolve-se na produção de sujeitos por meio de diversificadas estratégias discursivas. Ela disponibiliza linguagens para falar dos e para os sujeitos e sistemas conceituais para calcular as capacidades e condutas e calibrar a psique. Esse caráter produtivo advém do fato de que discursos não são meras interseções entre palavras e coisas, mas segundo Foucault (2005), são práticas que instituem aquilo de que falam. É assim que a subjetivação, mesmo não sendo um construto puramente lingüístico (ROSE, 2001), guarda fortes ligações com o discursivo, uma vez que este constitui, segundo Foucault (2005, p. 61), "um campo de regularidade para as diversas posições de subjetividade".

Implicadas em conduzir condutas, músicas produzem sujeitos e exercem governo, afinal "aquilo que faz com que um corpo, gestos, discursos e desejos sejam identificados e constituídos enquanto indivíduos é um dos primeiros efeitos de poder" (FOUCAULT, 2007a, p. 183). Músicas, assim como inúmeros outros artefatos da cultura da mídia, também constituem alvo privilegiado de estratégias de regulação da vida, de condução da conduta, de governo. Afinal, suas variadas capacidades de seduzir e interpelar por meio do canto, do movimento e da dança evidenciam aquilo que Foucault (2007b, p. 8) diz sobre o poder: que ele só é aceito e se mantém porque "produz coisas, induz ao prazer, forma saber, produz discurso", o que passarei a discutir adiante.

\section{QUANDO A MÚSICA SE FAZ CURRÍCULO, HÁ PEDAGOGIA E PRODUZEM-SE SUJEITOS}

Em 2009, uma senhora fluminense declara ter passado cinco horas com fome e sede para se espremer junto ao palco onde se apresentou a banda que lhe proporcionou uma das grandes emoções de sua vida. A mais de mil quilômetros dali, em meio à sala ainda com rabiscos de matemática na lousa, um casal de adolescentes encena uma aula de dança. Na internet, em um portal mantido pelo governo federal para subsidiar o trabalho de docentes em todo o país, um professor mineiro planeja uma aula voltada à coordenação e expressividade em Educação Infantil. Em outro site, uma jovem mãe de vinte e nove anos publica um vídeo de seu filhinho dançando na escola. Já que músicas não apenas fazem cantar, dançar e divertir, nenhuma surpresa diante desses episódios ${ }^{6}$, se aqui não houvesse uma trilha sonora em comum.

Conduzir e conectar corpos e vidas é efeito das artimanhas de um currículo, é efeito da

\footnotetext{
${ }^{6}$ Evidências desses episódios encontram-se em Maknamara e Paraíso (2015).
} 
pedagogia que lhe é específica, efeito de suas vontades de sujeito. Quando se vê um mesmo estilo musical seduzindo indivíduos a dançar na escola ou fora dela, fazer passar fome e sede, planejar aulas, é porque suas músicas divertem, alegram ou entristecem pessoas, mas também provocam sentimentos e desejos, inscrevem nos corpos marcas e normas consideradas desejáveis e necessárias, constituem um importante espaço aglutinador dos hábitos, saberes, sonhos, costumes e valores (MAKNAMARA, 2014). É produtivo, portanto, focalizar a dimensão constitutiva das músicas em nossas vidas naquilo que é ensinado e pode, ainda que de maneira incerta e transitória, vir a ser aprendido por meio delas.

Esse olhar sobre diferentes ensinamentos engendrados por artefatos culturais resulta de uma atenção àquilo que Birman (2000) denomina de "condição problemática da subjetividade na atualidade". Tal condição "impõe a os/as educadores/as a necessidade de estudos que articulem o educacional, o social, o histórico e o psicológico, que tratem da conexão entre aprendizagens e modos de ser sujeito, que não subestimem os liames entre processos de subjetivação e as variadas instâncias do pedagógico" (MAKNAMARA, 2011, p. 15). Aquela atenção e o reconhecimento dessa necessidade levaram-me a pesquisar conexões entre currículo, gênero e nordestinidade. Se há múltiplas formas com que gênero ${ }^{7}$ atravessa e dá espessura ao tecido social, em meu doutoramento escolhi investigar a produção do masculino e do feminino em músicas de forró eletrônico. Interessei-me pelos mecanismos de produção de masculinidades e feminilidades, os processos de subjetivação ${ }^{8}$ engendrados pelas técnicas e tecnologias acionadas nos discursos do referido estilo musical, a invenção de experiências generificadas como efeito da produtividade daquele currículo.

O forró eletrônico concorre, via gênero, para uma erosão das linhas de continuidade que historicamente forjaram uma idéia de nordestinidade. Gênero é a temática privilegiada nas músicas de forró eletrônico. Elas se voltam para as manifestações cotidianas de relações possíveis entre o masculino e o feminino e nelas buscam significados e formas de expressão, temáticas, assuntos, episódios e fenômenos para suas criações textuais. Por todo esse lugar privilegiado nas músicas de forró eletrônico, considerei que, se gênero tem constituído uma dimensão axial da invenção do Nordeste, também por meio de tal dimensão poderiam ser forjadas outras nordestinidades, para além do que usualmente tem sido considerado "nordestino".

O currículo do forró eletrônico regula nordestinidades porque ao mesmo tempo em que reforça antigos estereótipos que ajudaram a sedimentar uma determinada idéia do que seriam o Nordeste e seu povo, torna cada vez mais improvável defini-los por meio de um conjunto preciso, homogêneo e coerente de discursos, imagens e textos relativamente a gênero. As análises que realizei evidenciaram que o referido currículo ensina modos de ser sujeito na confusão de fronteiras entre o que seria ou não próprio do/a nordestino/a em termos de gênero. No sentido de ilustrar como um artefato cultural aparentemente inócuo coloca-se como máquina de ensinar, governa e produz sujeitos, sintetizarei alguns dos resultados da investigação, mas antes detalharei os procedimentos metodológicos que me

\footnotetext{
${ }^{7}$ Um conceito que expõe e possibilita analisar a contingência, as arbitrariedades e os investimentos de podersaber que fomentam a definição de masculinidades e de feminilidades (MAKNAMARA, 2011).

${ }^{8}$ Processos que "convocam indivíduos a assumir determinadas posições e a tornarem-se sujeitos de determinado tipo" (MAKNAMARA, 2011, p. 58) e dos quais resulta a constituição de subjetividades.
} 
levaram a tais resultados.

\section{Metodologia utilizada para ver e ouvir um currículo cultural}

As músicas aqui em questão foram analisadas mediante o emprego da análise discursiva inspirada nos trabalhos de Michel Foucault. Foram analisados fragmentos discursivos de 464 músicas de forró eletrônico, adotando elementos metodológicos inspirados nas análises foucaultianas que focalizam o discurso, entendido este como prática produtora de formas de sujeição e de esquemas de conhecimento (FOUCAULT, 2001). Desde Maknamara (2011, p. 63), tenho assumido que operar com esse tipo de análise implica em atentar a como determinados discursos vão se configurando em meio a relações de poder; significa, também, questionar sobre as condições de possibilidade e as regularidades a partir das quais determinados discursos concorrem para o exercício do poder e a produção de posições de sujeito.

O pensamento de Foucault nos traz as possibilidades de buscarmos em diferentes práticas sociais as condições pelas quais posições de sujeito são disponibilizadas em meio a relações de poder. Dito de outro modo, explorar a possibilidade de ler o texto do currículo do forró eletrônico foi consequência da compreensão de que o poder deixa marcas do seu exercício nas mais diferentes instâncias sociais. Para chegar a tais marcas, para ver o poder em ação no referido currículo, tomei o discurso como prática articuladora de elementos por meio dos quais efeitos de poder são traduzidos em fabricações de sujeitos. Esses elementos consistem nas táticas, estratégias, técnicas, mecanismos e tecnologias ${ }^{9}$ em ação nos fragmentos discursivos aqui analisados. Isso se deu por considerar que entre um discurso e as coisas das quais ele faz falar não há uma relação de mera correspondência e de continuidade, mas uma relação de poder. O discurso se liga intimamente ao poder e não traduz as coisas, mas deixa ver os efeitos de poder envolvidos na enunciação das coisas de que fala e faz falar (MAKNAMARA, 2011).

As análises empreendidas por Foucault no campo do discurso possibilitam uma apropriação no sentido de colocar em cena as maquinações pelas quais somos fabricados como tipos particulares de sujeitos. Nos discursos que compõem o currículo do forró eletrônico, busquei destacar tanto as regularidades discursivas quanto as descontinuidades que concorrem para a produção de verdades sobre sujeitos de gênero em conexão com a idéia de uma experiência da nordestinidade. Evidenciei como os discursos analisados produzem, repartem, hierarquizam e combinam significados historicamente ligados a masculinidades e feminilidades ditas "nordestinas". Para isso, atentei a quem nesses discursos nomeia e é nomeado, como também às formas como se dão tais nomeações. Mapeei as enunciações e interroguei os acionamentos de poder que nos discursos visavam a tipos específicos de experiências de "ser homem" e de "ser mulher" para que ouvintes possam tornar-se tipos particulares de sujeitos, como visto a seguir.

\section{Biopolítica de endereçamentos de gênero}

\footnotetext{
${ }^{9}$ Para detalhamento a respeito desses elementos de poder no discurso, ver Maknamara (2014). 
Em 27 de julho de 2008 o jornal Folha de São Paulo publicou o caderno especial "Jovem Século 21", apresentando o "mais completo perfil do jovem brasileiro" até então. Resultado de pesquisa do Datafolha junto a 1.541 jovens (entre 16 e 25 anos) em 168 cidades brasileiras, o caderno trouxe uma matéria intitulada "O Brasil do forró!", na qual se destacava que esse gênero musical despontava como o preferido de um quarto da juventude brasileira ${ }^{10}$. A matéria veio como uma espécie de termômetro do sucesso experimentado pelo forró eletrônico, um estilo de forró que emergiu no cenário da música nacional em meados da década de 1990 e que é responsável por grande parte do sucesso deste gênero musical que desponta como o preferido dentre jovens universitários/as ainda em 2019 (SOARES et al, 2019).

Não é difícil constatar a presença do forró eletrônico na vida estudantil de muitos/as brasileiros e brasileiras (MAKNAMARA e PARAÍSO, 2012, 2013). Contudo, suas músicas também se presentificam no cotidiano mais ordinário, evidenciando como a cultura penetra "em cada recanto da vida social contemporânea, fazendo proliferar ambientes secundários, mediando tudo" (HALL, 1997, p. 22, grifos dele). Tais músicas fizeram e fazem sucesso não apenas em todo o Brasil, mas também no exterior, sendo que a movimentação em torno delas já gerou milhares de postos de trabalho. Em contrapartida, intérpretes de forró eletrônico participam de espetáculos cênicos, de ensaios de moda, emplacam hits em festas tradicionais, arrancam elogios de "autoridades" de outros gêneros musicais e são ídolos de outros ídolos nacionais ${ }^{11}$. Mas como se garante tamanha captura?

Os endereçamentos ${ }^{12}$ do forró eletrônico exercem uma biopolítica que transforma sua audiência em público forrozeiro. As músicas ${ }^{13}$ de forró eletrônico disponibilizam, demandam e reivindicam modos de ser comuns a os/as forrozeiros/as, tanto que as bandas usam referir-se a seu público como uma nação forrozeira. Esse currículo demanda e produz sujeitos porque incita que sua audiência, ainda que não preste atenção a suas letras ou reflita sobre elas, estabeleça relações com suas músicas, quando o que está em jogo em relações desse tipo é uma "busca da identificação com a mensagem da canção", em termos daquilo "que parecem desejar [ou não] para suas vidas" (GARBIN et al, 2003, p. 3). As músicas de forró eletrônico são endereçadas de forma que o estilo de vida por elas demandado ganhe corpo na figura do/a forrozeiro/a mediante uma "tecnologia corporeísta de gênero". Tal tecnologia distribui diferencialmente entre o masculino e o feminino atributos e capacidades corporais considerados forrozeiros e opera segundo a atuação de um "mecanismo da comemoração". Indivíduos que ouvem forró eletrônico são biopoliticamente convocados a tornarem-se sujeitos de uma "nação forrozeira", uma comunidade imaginada e que se imagina portadora de atributos ${ }^{14}$ que fogem

\footnotetext{
${ }^{10}$ Evidências dessa preferência juvenil pelo forró encontram-se em Maknamara (2010).

${ }^{11}$ Evidências dessa "ubiquidade" do forró eletrônico encontram-se em Maknamara e Paraíso (2011).

12 Problematizado por Ellsworth (2001) em seus estudos de cinema, trata-se de um conceito que desloca as situações de ouvir música de um caráter meramente voluntário, de livre escolha, para um evento relacional. Graças a esse conceito pude argumentar que as músicas de forró eletrônico são "pensadas" de modo a disponibilizar determinadas posições de sujeito e deixam traços das suposições que fazem a respeito de sua audiência, de seu público.

${ }^{13}$ Os trechos das músicas analisadas encontram-se em Maknamara (2011).

${ }^{14}$ Como vivemos tempos de identificação entre sujeito e corpo, os atributos privilegiados por esse currículo constituem saberes ligados à corporeidade (motricidade, cinestesia, dança, semiologia, alcoolismo) e também à sexualidade.
} 
daqueles estereótipos historicamente creditados ao Nordeste e a seus habitantes.

Na figura de um cowboy, de uma robô ou de uma rendida-arrependida, as músicas de forró eletrônico disponibilizam a forrozeiros/as experiências de nordestinidades mesmo quando se está a quilômetros do Nordeste - ser forrozeiro/a traz a qualquer um/uma a possibilidade de ser nordestino/a em qualquer local. Mas o mesmo currículo também investe sobre a produção da nação forrozeira como algo tão ficcional, contingente e mutável quanto a nordestinidade que se costumou acoplar ao forró: ser forrozeiro/a traz a qualquer um/uma a possibilidade de deixar de ser nordestino/a, no momento em que qualquer ouvinte de forró eletrônico pode tornar-se sujeito (uma "pegadora", uma "bichinha arrumada" ou um "vagabundo", por exemplo) de um público específico. O forró eletrônico não deixa de trair a nordestinidade tanto quanto possibilita que ela seja assimilada e reinventada. Nessa traição, ele mostra a ficção de uma invenção - da sua própria e do Nordeste que o possibilitou.

No currículo do forró eletrônico a nação forrozeira se afirma, portanto, sem reivindicar uma história ou tradição que serviriam de base para marcar certa identidade fixa, estável e unificada. $\mathrm{O}$ currículo do forró eletrônico não funciona privilegiando vetores identitários e regionalistas ou, pelo menos, não parece partir deles ou com eles trabalhar para levantar a "bandeira nordestina", como deliberadamente querem outros estilos de forró e seus/suas defensores/as. Produzir nordestinos/as não é a vocação do currículo do forró eletrônico ou, pelo menos, não é o eixo de sua proposta. Ainda que algumas das posições de sujeito que identifiquei conectem-se a determinados modos de ser que foram e vêm sendo forjados como nordestinos, nas quatrocentas e sessenta e quatro músicas investigadas não ouvi serem pronunciados os termos "Nordeste", "nordestino", "nordestinidade".

\section{O dispositivo pedagógico da nordestinidade no currículo do forró eletrônico}

Gatinha Manhosa, Cheiro de Menina, Ferro na Boneca. Brinquedo de Menina, Desejo de Menina, Collo de Menina. Moleka 100 Vergonha, Garota Safada, Dezmantelados do Forró, Casadões do Forró. Solteirões do Forró, Mauricinhos do Forró, Taradões do Forró. Saia Rodada, Fogo na Saia. Mulher Fogosa, Mulher Chorona, Mulheres Perdidas. Alguns nomes de bandas de forró eletrônico parecem não deixar dúvidas: nesse estilo musical, tudo é uma questão de ser e de posicionar-se como homem ou mulher.

A centralidade do gênero nas músicas de forró eletrônico, ainda que seja marcante, não é inesperada. Se gênero tem primazia na significação de relações de poder (SCOTT, 1995) e o currículo do forró eletrônico não escapa de tais relações, é previsível que suas músicas orquestrem diversas situações acerca de relações entre homens e mulheres. Entretanto, em tais músicas, gênero não é apenas o componente privilegiado de suas temáticas, mas se afirma como importante dimensão da vida de seus/suas ouvintes, disponibiliza racionalidades a partir das quais eles e elas podem pensar sua existência. É no sentido de suas estratégias para governar que o forró eletrônico, assim como outros estilos musicais e demais artefatos culturais, deve interessar cada vez mais ao campo educacional.

Há um "dispositivo pedagógico da nordestinidade" que tem no forró eletrônico um campo privilegiado de sua atualização e em gênero uma de suas principais linhas de força. Nas músicas de 
forró eletrônico, são engendradas continuidades e descontinuidades, condensações e dispersões enunciativas que concentram e diluem experiências da nordestinidade. Concorre para tal atualização uma "tecnologia sistemática do gênero" que toma assimetrias entre masculino e feminino como princípio de inteligibilidade das relações sociais. Essa tecnologia opera segundo a atuação concomitante de dois mecanismos: um "mecanismo inventariador" e um "mecanismo retro-alimentador" de gênero. O primeiro funciona instaurando chaves para a identificação das linhas de dualização dos sexos, enquanto o segundo atua normalizando a complementaridade entre eles.

Músicas têm instaurado tipos muito particulares de relações de poder ligadas a gênero, as quais subsidiam a produção de posições de sujeito igualmente peculiares. Tem feito parte de tal repertório uma série de tipos femininos e masculinos ao mesmo tempo inventariados e produzidos pelo currículo do forró eletrônico. Há feminilidades e masculinidades mil à disposição da audiência forrozeira! Há safadas, bichinhas arrumadas, vencedores, perdidas, mulheres-do-babado, marrentos, ioiôs, barbies, rendidas-arrependidas, robôs, caras, astronautas, meninas forrozeiras, pegadoras, gatinhos, gaviões, bons-de-copo, vagabundos, homens-do-mundo, detentos, carcereiros, libertas, aeronautas, cowboys, enfermeiras e doentes que assinalam tanto para reiterações de formas já desgastadas quanto para a emergência de singularidades em se tratando de masculinidades e de feminilidades em conexão com o ser nordestino/a. E, por mais que a construção das masculinidades e das feminilidades não seja algo estanque, "as músicas aqui investigadas sugerem ser possível, e com relativa precisão, desenvolver amostragens, identificar, nomear, classificar, ordenar e hierarquizar gêneros" (MAKNAMARA e PARAÍSO, 2019).

Ao demandar e produzir formas de pensar, dizer e viver modos de ser masculino e feminino, o currículo do forró eletrônico nos educa e nos faz lembrar de que gênero concerne às formas com que, historicamente, mulheres e homens têm aprendido seus distintos lugares sociais. Insistir na dimensão discursiva do gênero implica em reconhecer que o modo como se fala daquilo que seria pertinente ao masculino e ao feminino produz sujeitos, concorre para a produção de posições de sujeito generificadas. O caráter discursivo do gênero, aqui problematizado em suas conexões com nordestinidades, mostra que não nascemos homens ou mulheres, mas que nosso "ser homem" e "ser mulher" é forjado por meio dos discursos que nos interpelam, nos ensinam e nos produzem como sujeitos de gênero. E "quando a mídia disputa com a escola competências para ensinar, vale atentar para diferentes ensinamentos sobre modos de ser sujeito" (MAKNAMARA e PARAÍSO, 2019).

Assim, o currículo do forró eletrônico atualiza o dispositivo pedagógico da nordestinidade ao demandar tipos masculinos e femininos componentes de um suposto "modo de ser nordestino" e ao fazer conviver junto a eles figuras e estilos de vida até então pouco visíveis, inexistentes ou mesmo associadas a outros dispositivos. O dispositivo pedagógico da nordestinidade é, portanto, inseparável de processos de subjetivação que, no forró eletrônico, funcionam através do acionamento de tecnologias de classificação e de divisão entre indivíduos e no interior de cada um deles. Tais formas de ver e de falar por meio dos mecanismos de poder do referido dispositivo são sempre contingentes, porque historicamente construídas. Dessa forma, a atualização do dispositivo pedagógico da nordestinidade pelo forró eletrônico não se dá sem a justaposição e/ou acréscimo de outros enunciados que vêm possibilitar a configuração da nordestinidade de outras formas. Cabe, portanto, 
atentar para outros mecanismos e tecnologias de governo segundo os quais diferentes currículos culturais nos tornam sujeitos de gênero por meio de seus ensinamentos. Afinal, se historicamente há inúmeros repertórios que têm sido montados de modo circunscrito a estereótipos e desigualdades de gênero, é também em torno das relações entre masculino e feminino que eles podem ser desmontados.

\section{PARA PROSSEGUIR A DISCUSSÃO COM OUTROS ARTEFATOS CULTURAIS}

Se, para Kellner (2001), a música ocupa uma posição central no cenário cultural contemporâneo, no qual há uma cultura da mídia que "passou a dominar a vida cotidiana" (p. 11), que dizer a respeito de investigar tantos outros artefatos que não param de emergir e de nos interpelar? Considerando a insidiosidade de artefatos culturais na constituição de modos de ser sujeito, trago nesta seção contribuições para se somar àquelas já disponíveis a quem se lança à tarefa de investigar tais artefatos segundo o referencial aqui adotado. Elaboro essas contribuições a partir de Silva (1997), Paraíso (2010) e Maknamara $(2011,2015)$, reconhecendo a simplificação e a provisoriedade do que passarei a propor, mas esperando que possa ter utilidade a alguém.

Pensei em um caminho possível na interpelação de artefatos culturais diversos como desenhos animados, filmes, propagandas, novelas, narrativas seriadas (e suas variações em séries, minisséries, webséries, seriados, etc.), kits de literatura, HQs, mangás, fotografias, exposições... Sinteticamente, trata-se das possibilidades de abordar artefatos culturais como máquinas de ensinar, como textos culturais, como produtores de sujeitos e/ou como instrumentos de governo. Esquematizo essas possibilidades em termos do que buscar e abordar, na pesquisa com um artefato, para perseguir o foco conforme seja o interesse da problematização. Exemplifico com narrativas seriadas, um artefato que tem "dado muito o que falar" nos dias atuais:

Narrativas seriadas como máquinas de ensinar:

O que buscar e abordar?

- dimensões e valores culturais que são privilegiados;

- linguagens e saberes mobilizados para ensinar;

- formas de capturar o tempo e o envolvimento da audiência;

- significados a fixar e a ensinar.

O que está em foco: a fabricação e o mecanismo do próprio artefato.

Narrativas seriadas como textos culturais:

O que buscar e abordar?

- enunciações e conceitos em cena;

- formas de inscrição com as quais são apresentados os elementos das narrativas (pessoas, culturas, estilos, cenários...), incluindo as nomeações (de objetos, indivíduos, realidades);

- linguagens e códigos usadas para apresentar os significantes (representações); 
- divulgações de modos de vida usadas para reforçar verdades (ligadas a diferentes marcadores sociais, tal como gênero, geração, classe, raça/etnia, origem geográfica, etc.), as escolhas feitas para tornar esses modos de vida inteligíveis e aceitáveis, os saberes e valores que as narrativas seriadas estão a negar, a excluir, a preservar e a instituir/afirmar.

O que está em foco: o sistema de significação do artefato que o faz produto e produtor de uma cultura específica.

Narrativas seriadas como produtoras de sujeitos:

O que buscar e abordar?

- quem o artefato pensa atingir/quem ele pensa ser seu público;

- quem o artefato quer que seja seu público/como ele quer que seja esse público;

- definições de personagens/cenários/focalizações/localizações no enredo como frentes de captura de público e suposições de efeito sobre esse público.

O que está em foco: os modos de endereçamento do artefato e suas estratégias para dialogar com seu público.

Narrativas seriadas como instrumento de governo:

O que buscar e abordar?

- o que é escolhido (e quem escolhe) como tema e problema relativamente a modos de vida;

- estratégias discursivas para governo dos outros (governo mútuo);

- estratégias discursivas para governo de si (autogoverno);

- utilidade dessas estratégias para governo pelo Estado;

- buscar saberes e relações de poder de diferentes tipos (pastoral, biopolítico, etc...).

O que está em foco: o cálculo das habilidades dos indivíduos e a maximização de sua utilidade como sujeitos.

Trata-se de uma contribuição que considera, como Woodward (2008), que todo artefato cultural regula a vida social conectando suas formas de representação, articulação e consumo e as identidades a eles associadas. Nesta minha proposição, cabe a quem investiga o artefato captar e evidenciar seu(s) "princípio de inteligibilidade", ou seja, "a idéia que regula um exercício particular de poder, uma maneira de pensar, analisar e definir os elementos que, em sua natureza e relações, concorrem para efeitos específicos de poder" (MAKNAMARA, 2011, p. 132). São temas e focos de questionamentos possíveis para estudos afeitos a pesquisas pós-críticas em educação interessados em investigar as tramas de artefatos culturais que ensinam, demandam e produzem sujeitos e terminam por envolverIhes em estratégias de governo quando aparentemente apenas fazem divertir.

\section{CONCLUSÃO}

Os diferentes artefatos acionados pela cultura da mídia podem ser lidos como textos: composições linguísticas que, mais que mediar e comunicar relações entre palavras e coisas, incorporam e 
produzem significados, saberes, valores. Textos produzem e disponibilizam formas particulares de ver, saber, sentir e descrever e, assim, concorrem para processos de subjetivação. Como textos, artefatos culturais são textos curriculares também, quando se compreende currículo como qualquer forma de organização de conhecimentos "envolvidos numa economia do afeto que busca produzir certo tipo de subjetividade e identidade social" (SILVA, 2002, p. 136).

As possibilidades de leitura aqui discutidas demonstram que artefatos culturais midiáticos, "artes feitas na cultura da mídia", constituem currículo. Dado que, da perspectiva teórica aqui adotada, toda problematização de currículo é uma questão de poder e de constituição de sujeitos, tenho entendido currículo como produto da disponibilização de formas de raciocínio, saberes, valores, afetos e comportamentos que contribuem, através de estratégias e técnicas específicas, para a formação de pessoas ao atribuir significados a lugares, coisas, fenômenos, práticas e/ou sujeitos. Afinal, currículos incorporam e produzem significados, saberes, valores e verdades, sendo inevitável estabelecer ligações entre eles e processos de subjetivação.

Já se sabia que, em se tratando da conexão entre currículo e produção de sujeitos, "a escolha sobre que saberes selecionar, que significados priorizar, que estratégias adotar tem efeitos importantes no tipo de sociedade que contribuímos para construir" (PARAíSO, 2010, p. 54). Agora parece inadiável que se tenha cada vez mais atenção sobre os currículos de artefatos culturais. Sobretudo quando não somos nós que selecionamos seus saberes ou priorizamos os significados que disponibilizam, é urgente fazer uso dos instrumentais de que dispomos para analisar suas estratégias e entender seus efeitos e, assim, explicitar as artimanhas que Ihes fazem tão eficazes em suas capacidades de recrutar, produzir e regular sujeitos.

\section{REFERÊNCIAS}

1. BIRMAN, Joel. Subjetividade, contemporaneidade e educação. In: CANDAU, Vera (Org.). Cultura, linguagem e subjetividade no ensinar e aprender. Rio de Janeiro: DP\&A, 2000, p. 11-28.

2. CAMOZZATO, Viviane $\mathrm{C}$. Sociedade pedagógica e as transformações nos espaços-tempos do ensinar e do aprender. Em Aberto. Brasília, v. 31, n. 101, p. 107-119, 2018. DOI: http://dx.doi.org/10.24109/2176-6673.emaberto.31i101.3526.

3. CORAZZA, Sandra. O que quer um currículo? - pesquisas pós-críticas em educação. 3. ed. Petrópolis: Vozes, 2004. 150 p.

4. COSTA, Marisa V. Poder, discurso e política cultural: contribuições dos Estudos Culturais ao campo do currículo. In: LOPES, Alice C. e MACEDO, Elizabeth (Orgs.). Currículo: debates contemporâneos. 2. ed. São Paulo: Cortez, 2005b, p. 133-149. 
5. ELLSWORTH, Elisabeth. Modos de endereçamento: uma coisa de cinema; uma coisa de educação também. In: SILVA, Tomaz Tadeu da (Org.). Nunca fomos humanos: nos rastros do sujeito. Belo Horizonte: Autêntica, 2001, p. 07-76.

6. FISCHER, Rosa M. B. O estatuto pedagógico da mídia: questões de análise. Educação \& Realidade. Porto Alegre, v. 22, n. 02, p. 59-80, 1997.

7. FOUCAULT, Michel. História da Sexualidade I. 14. ed. Rio de Janeiro: Graal, 2001. 152 p.

8. FOUCAULT, Michel. A arqueologia do saber. Rio de Janeiro: Forense Universitária, 2005. 236 p.

9. FOUCAULT, Michel. Soberania e disciplina. In: MACHADO, Roberto (Org.). Microfísica do Poder. 23. ed. Rio de Janeiro: Graal, 2007a, p. 179-191.

10. FOUCAULT, Michel. Verdade e poder. In: MACHADO, Roberto (Org.). Microfísica do Poder. 23. ed. Rio de Janeiro: Graal, 2007b, p. 01-14.

11. GARBIN, Elisabete M.; SANTOS, Lisiane G.; DAROS, Vivian S. Eu sou o que eu curto, eu não tenho uma coisa certa assim... Identidade Musicais Juvenis. III Congresso Internacional Lassalista de Educação: inclusão e exclusão da criança, do jovem e do adulto na educação. CD-ROM. Canoas, 2003. 14 p.

12. GIROUX, Henry A. A disneyzação da cultura infantil. In: SILVA, Tomaz T. da e MOREIRA, Antonio F. B. (Orgs.). Territórios contestados: o currículo e os novos mapas políticos e culturais. 5. ed. Petrópolis: Vozes, 2001, p. 49-81.

13. HALL, Stuart. A centralidade da cultura: notas sobre as revoluções culturais do nosso tempo. Educação \& Realidade. Porto Alegre, v. 22, n. 02, p. 15-46, 1997.

14. KELLNER, Douglas. A cultura da mídia - estudos culturais: identidade e política entre o moderno e o pós-moderno. Bauru: EDUSC, 2001. 454 p.

15. KELLNER, Douglas. Lendo imagens criticamente: em direção a uma pedagogia pós-moderna. In: SILVA, Tomaz Tadeu da (Org.). Alienígenas na sala de aula: uma introdução aos estudos culturais em educação. Petrópolis: Vozes, 2003, p. 104-131.

16. MAKNAMARA, Marlécio. O dispositivo pedagógico da nordestinidade no currículo do forró eletrônico. In: PARAíSO, Marlucy A. (Org.). Pesquisas sobre currículos e culturas: temas, embates, problemas e possibilidades. Curitiba: Editora CRV, 2010, p. 95-115. 
17. MAKNAMARA, Marlécio. Currículo, gênero e nordestinidade: o que ensina o forró eletrônico? 2011. 151f. Tese (doutorado) - Faculdade de Educação, Universidade Federal de Minas Gerais, Belo Horizonte, 2011.

18. MAKNAMARA, Marlécio. Afinidades e afinações pós-críticas em torno de currículos de gosto duvidoso In: PARAíSO, Marlucy A.; MEYER, Dagmar E. E. (Orgs.). Metodologias de pesquisas pós-críticas em educação. 2. ed. Belo Horizonte: Mazza, 2014, p. 157-176.

19. MAKNAMARA, Marlécio. Natureza e desenhos animados: conexões com a formação docente em ciências. Alexandria (UFSC). Florianópolis, v.8, p.75 - 87, 2015. DOI: https://doi.org/10.5007/19825153.2015v8n2p75.

20. MAKNAMARA, Marlécio; PARAÍSO, Marlucy A. Problemas de gênero para escutar o forró eletrônico com ouvidos de educador/a. In: MAKNAMARA, Marlécio (Org.). Encontros em educação: infância, história, política, cultura, meio ambiente.... João Pessoa: EdUFPB, 2011, p. 163-172.

21. MAKNAMARA, Marlécio; PARAísO, Marlucy A. Forró eletrônico: uma questão de governo... Uma questão também de educação? Exitus. Santarém, v. 2, n. 1, p. 141-156, 2012.

22. MAKNAMARA, Marlécio; PARAíso, Marlucy A. Biopolítica de endereçamentos de gênero no currículo do forró eletrônico. Linhas. Florianópolis, v. 16, n. 30, p. 180-213, 2015. DOI: http://dx.doi.org/10.5965/1984723816302015180.

23. NAPOLITANO, Marcos. História \& Música: história cultural da música popular. 2. ed. Belo Horizonte: Autêntica, 2005. 120 p.

24. PARAÍSO, Marlucy A. Currículo e mídia educativa brasileira: poder, saber e subjetivação. Chapecó: Argos, 2007. 274 p.

25. PARAÍSO, Marlucy A. Currículo e formação profissional em lazer. In: ISAYAMA, Hélder F. (Org.). Lazer em Estudo. Campinas: Papirus, 2010, p. 27-58.

26. ROSE, Nikolas. Inventando nossos eus. In: SILVA, Tomaz Tadeu da (Org.). Nunca fomos humanos: nos rastros do sujeito. Belo Horizonte: Autêntica, 2001, p. 137-204.

27. SCOTT, Joan. Gênero: uma categoria útil de análise histórica. Educação \& Realidade. Porto Alegre, v. 20, n. 02, p. 71-99, 1995.

28. SILVA, Tomaz Tadeu da. Educação pós-crítica e formação docente. Cadernos de Educação, Pelotas, v. 8, p. 155-170, 1997. 
29 . Belo Horizonte: Autêntica, 2001a. 120 p.

30. Deleuze. Anais da XXIV Reunião Anual da ANPED. Caxambu: GT Currículo, 2001b. 16 p.

31. SILVA, Tomaz Tadeu da. Documentos de identidade: uma introdução às teorias do currículo. 2. ed. Belo Horizonte: Autêntica, 2002. 154 p.

32. SILVA, Tomaz Tadeu da. Currículo e identidade social: territórios contestados. In: SILVA, Tomaz Tadeu da. (Org.). Alienígenas na sala de aula: uma introdução aos estudos culturais em educação. 5. ed. Petrópolis: Vozes, 2003, p. 190-207.

33. SOARES, Beatriz A.; MONTEIRO, Luiz H. B.; NIQUINI, Claudia M.; LOPES, Priscila; NOBRE, Juliana N. P. Dialogando com estudantes: as preferências das danças no meio universitário. Enciclopédia Biosfera. Goiânia, v.16 n.29, p. 1-12, 2019.

34. SOVIK, Liv. O rap desorganiza o carnaval: globalização e singularidade na música popular brasileira. Caderno CRH. Salvador, n. 33, p. 247-255, 2000. DOI: http://dx.doi.org/10.9771/ccrh.v13i33.18578.

35. WOODWARD, Kathryn. Identidade e diferença: uma introdução teórica e conceitual. In: SILVA, Tomaz Tadeu da. (Org.). Identidade e diferença: a perspectiva dos estudos culturais. 8. ed. Petrópolis: Vozes, 2008, p. 07-72.

\section{Marlécio Maknamara}

Pós-Doutor pela La Trobe University (Austrália). Doutor em Educação pela UFMG. Professor dos Programas de Pós-Graduação em Educação da UFBA e da UFRN. Líder do ESCRE(VI)VER: Grupo de Estudos e Pesquisas com Narrativas em Educação/CNPq e Membro Pesquisador do Grupo de Estudos e Pesquisas sobre Currículos e Culturas/CNPq.

\section{Como citar este documento:}

MAKNAMARA, Marlécio. Quando artefatos culturais fazem-se currículo e produzem sujeitos. Reflexão e Ação, Santa Cruz do Sul, v. 28, n. 2, jun. 2020. ISSN 1982-9949. Disponível em: $<$ https://online.unisc.br/seer/index.php/reflex/article/view/14189>. Acesso em doi:https://doi.org/10.17058/rea.v28i2.14189. 
Reflexão e Ação [ISSN 1982-9949]. Santa Cruz do Sul, v. 28, n. 2, p. 58-72, mai./ago. 2020. https://online.unisc.br/seer/index.php/reflex/index 